\title{
La dramática de Shakespeare vista por Cándido Pérez Gállego *
}

\author{
Honesto Herrera
}

Shakespeare, una palabra que pronunciada de acuerdo a la fonética hispánica provocó la carcajada de un auditorio y la consiguiente improvisación de una conferencia en inglés a cargo del ilustre hombre de letras don Ramón Menéndez Pidal, es hoy también motivo de una obra crítica : cargo de otro ilustre de las letras, C. Pérez Gállego.

Si en otra ocasión el mencionado crítico publicó Shakespeare y la Política, ahora vuelve sobre el mismo autor publicando Dramática de Shakespeare, publicación que deja entrever el comienzo de una constante de publicaciones en torno a Shakespeare después de haber estudiado temas tan variados como los Angry Young Men y la Golden Age de la novela americana. El motivo de esta polarización probablemente estriba en el hecho de que, aunque la obra de Shakespeare ha sido y es muy estudiada, todavía contiene tal actualidad y vigencia que es capaz de arrancar estudios de investigación de personas con dedicación exclusiva.

La obra de C. Pérez Gállego tiene dos partes con orientación distinta, si la primera gira en torno a unos estudios monográficos de dos tragedias, dos comedias y una obra histórica, en la segunda nos presenta unos apuntes para el estudio de toda la obra de Shakespeare.

El Rey Enrique $I V$ constituye el primer estudio monográfico, en él se analiza la conducta de un Falstaff que ha sido corruptor antes que educador y en el que se apunta también a la teoría de la regeneración. Teoria de actualidad en escritores de la categoría de N. Frye y Mircea Elíade.

* Pérez Gállego, C., 1974. - Dramática de Shakoeprore, Ed. del Pórtico, 308 pp., Zaragoza. 
En Hamlet, la obra más estudiada por la crítica mundial, se encuentra como idea sorprendente y nueva ese condicional del que habla C. Pérez Gállego cuando dice que Gertrude y Claudio son desde el principio «final feliz», «y lo hubieran sido siempre de no ser por ese estudiante empeñado en obedecer designios dudosos».

Troilus se estudia bajo el punto de vista del canje de Cressida por Antenor, que es la causa de una lingüística peculiar a lo largo de la obra.

En Rey Lear, cuando se analiza la estructura de los hechos, se tiene la sensación de que estamos ante Propp, con una variante de sustitución; si en Propp se trata de los elementos que constituyen el cuento, aquí se habla del conjunto de elementos que, ordenados progresivamente, desembocarán en tragedia.

Finalmente, cuando se llega a Pericles vemos que encaja perfectamente con la «teoría de los logros» que, más o menos encubierta, aparece en las distintas monografías estudiadas. Mientras en Pericles se trata de sacar a la vida a la mujer que es causa de una peregrinación por el mundo, en las otras monografías vemos a un padre queriendo reconstruir una familia, la conquista de una corona, de una mujer o un Hamlet que va a empezar una lucha que le llevará a la muerte por aguar un «final feliz».

En la segunda parte, C. Pérez Gállego trata de penetrar en los distintos elementos que dan teatralidad a la obra. Con rigor científico somete a examen a todo el mosaico de elementos sobre los que se apoya el proceso dramático. Va analizando progresivamente el binomio estímulo-respuesta, los soliloquios y el modo cómo Shakespeare va resolviendo la dinámica de la obra a través de esos continuos saltos en el espacio y en el tiempo. Cuando se detiene en el texto nos dice que cualquier palabra, gesto, movimiento, encaja en el contexto de la obra, del escenario, de la socidad de Shakespeare. En este análisis nos descubre también C. Pérez Gállego cómo Shakespeare, autor del «teatro del mundo», es autor de teatro para un mundo occidental, ya que los temas del río, del caballo mágico de Chehjov, la peregrinación, la puerta que lleva al cielo, al Absoluto, no aparecen en su obra.

Después de comentar cómo la «belleza maldita» de Helena lleva consigo «simbólicamente» la guerra a griegos y troyanos, se detiene en la idea de jardín en Shakespeare. La naturaleza toma una doble vertiente en su obra, aparecen jardines y bosques. Los jardines para C. Pérez Gállego tienen valor de lugar recóndito, de zona sagrada, lugar ideal para una cita con la intimidad en cualquiera de las obras. Los bosques tienen connotaciones directas con el «exilio». Entre ambos entornos vegetales en 
Dramática de Shakespeare aparece un tercero al que nadie había prestado atención. Se trata de esas amplias llanuras en las que los personajes caminan «poseídos» por sus ideas, para quienes «los exteriores» no cuentan, en las que aparece Héctor atado a la cola del caballo y en las que se montan gran parte de los escenarios de Enrique $I V$, Enrique $V$ y Enrique VI.

En la Conclusión estudia los modelos básicos de cualquier tipo de realización shakesperiana. El entrar y salir de los actores, los diálogos, los soliloquios, todo cuenta en el comportamiento de los personajes.

Son tantos los factores positivos, que hacer un balance final constituye un escollo difícil de salvar, por lo que dejo a la iniciativa del lector hacer su propio balance final. Dramática de Shakespeare es una de las obras claves para ponernos en contacto con el inmortal Shakespeare. En ella C. Pérez Gállego va descodificando el sistema lingüístico, mímico y escenográfico que usa Shakespeare; es «conditio sine qua non» para captar el significado y espíritu de su obra.

Para terminar diré que en esta obra de nuevo se encuentran esas constantes de creación personal similares a las de un N. Frye, I. Kott, M. Elíade, por las que lo identificamos a lo largo de su obra crítica. 
